\title{
Notas sobre Coelidiana Oman (Hemiptera, Cicadellidae, Neocoelidiinae) e descrição de três novas espécies do Brasil ${ }^{1}$
}

\author{
Larissa De B. Chiamolera ${ }^{2} \&$ Rodney R. Cavichioli ${ }^{3}$ \\ ${ }^{1}$ Contribuição número 1486 do Departamento de Zoologia, Universidade Federal do Paraná. \\ 2 E-mail: laridbc@hotmail.com \\ ${ }^{3}$ Departamento de Zoologia, Universidade Federal do Paraná. Caixa Postal 19020, 81531-980 Curitiba, Paraná, Brasil. \\ E-mail: cavich@ufpr.br. Bolsista do CNPq (Proc. 303451/2002-5).
}

\begin{abstract}
Notes on Coelidiana Oman (Hemiptera, Cicadellidae, Neocoelidiinae) and description of three new species from Brazil. Three new species of Coelidiana Oman, 1936 are described and illustrated: Coelidina bella sp.nov. (Sinop, Mato Grosso); C. stricta sp.nov. (Ariquemes, Rondônia) and C. diminuta sp.nov. (Bebedouro, São Paulo). Coelidiana sinopensis (Chiamolera \& Cavichioli, 2000) comb. nov. (formely in Biza Walker). New geographical distribution data are also recorded for Coelidiana croceata Osborn, 1923; C. brasiliensis Linnavouri, 1965 and $C$. ferruginea Chiamolera \& Cavichioli, 2000. A key to species is provided.
\end{abstract}

KEY WORDS. Key to males, new combination, new records.

Resumo. Três novas espécies de Coelidiana Oman, 1936 são descritas e ilustradas: Coelidiana bella sp. nov. (Mato Grosso, Sinop), C. stricta sp. nov. (Rondônia, Ariquemes) e C. diminuta sp. nov. (São Paulo, Bebedouro). Uma nova combinação é proposta: Coelidiana sinopensis (Chiamolera \& Cavichioli, 2000) comb. nov. (Biza Walker) e novas ocorrências são registradas. Novos dados de distribuição geográfica são registrados para: Coelidiana croceata Osborn, 1923; C. brasiliensis Linnavuori, 1965 e C. ferruginea Chiamolera \& Cavichioli, 2000. Uma chave para as espécies é apresentada.

PALAVRAS CHAVES. Chave para machos, nova combinação, novos registros.

OMAN (1936) descreveu Coelidiana, incluindo-o em Jassinae. Designou como espécie-tipo, Neocoelidia rubrolineata Baker, 1898 do Brasil e transferiu para este gênero as seguintes espécies da América do Sul: Neocoelidia bimaculata Baker, 1898; N. modesta Baker, 1898; N. inflata Osborn, 1923; N. croceata Osborn, 1923. Diferenciou Coelidiana de Neocoelidia Gillete \& Baker, 1895 por ter o aspecto geral mais alongado, possuir carena na transição entre a coroa e a face e as asas estenderem bem além da extremidade do abdômen. Difere também de Chinaia Brunner \& Metcalf, 1934 pela presença de carena entre a coroa e a face e por ter apenas três células apicais na asa posterior.

Oman (1949) ao propor Neocoelidiinae, transferiu Coelidiana para esta subfamília. DeLong (1953) descreveu três novas espécies de Coelidiana: C. spina, C. bidentata e C. (Nelidina) defila, bem como propôs um gênero novo: Acocoelidia, relacionando-o com Coelidiana.

Kramer (1959) transferiu Chinaia undata Linnavuori, 1956 para Coelidiana., LinNavuori \& Heller (1961) descreveram duas novas espécies: C.(Stenocoelidia) flavida e C. (Coelidiana) rotundiceps.

Kramer (1964), ao revisar Neocoelidiinae, sinonimizou Acocoelidia DeLong, 1953 (espécie-tipo: Acocoelidia unipunctata DeLong) com Coelidiana e incluiu, também, as seguintes espé- cies: C. coronata (Ball, 1916) e C. croceata (Osborn, 1923), esta última já tendo sido incluída por OMAN (1936). Além de incluilas, apresentou uma diagnose, já que essas espécies não tinham sido estudadas desde a sua descrição original. Afirmou que as espécies de Coelidiana distribuem-se desde o sul do México até o Brasil. Nesse mesmo trabalho transferiu C. inflata (Osbron, 1923) para Xenocoelidia Kramer, 1959 e C. modesta (Baker, 1898) para Coelana DeLong, 1953.

LiNNAVUORI (1965) descreveu quatro novas espécies de Coelidiana: C. brasiliensis, C. signaticeps, C. distinctissima e C. lurida, as duas últimas baseadas apenas em fêmeas.

KRAMER (1967) revisou Coelidiana propondo quatro novas espécies: $C$. colens, $C$. ancora, $C$. durata e $C$. patrator e registra 15 espécies para o gênero. Colocou as espécies $C$. coronata (Ball, 1916), C. distinctissima Linnavuori, 1965 e C. lurida Linnavuori, 1965 em "incertae sedis" por terem sido descritas com base em um único espécime fêmea. No entanto, omitiu $C$. rotundiceps Linnavuori \& Heller, 1961.

DeLong \& Kolbe (1975) descreveram Coelidiana plaga.

Chiamolera \& Cavichioli (2000b) descreveram C. ferruginea, do Brasil e Freytag (2000) descreveu uma espécie das Ilhas Galápagos: C. krameri. 
As técnicas para o preparo de genitália de macho seguem OMAN (1949), com pequenas alterações; a terminologia adotada na descrição das espécies é a de Kramer (1964) e Young (1968), exceto para as estruturas da cabeça, que segue Hamilton (1981) e Mejdalani (1998). As medidas são fornecidas em milímetros.

Estudando os espécimes depositados na "Coleção de Entomologia Pe. Jesus Santiago Moure" do Departamento de Zoologia da Universidade Federal do Paraná (DZUP) e da Coleção do Instituto Nacional de Pesquisas da Amazônia (INPA), são propostas três novas espécies, cujas descrições são fornecidas adiante, bem como uma chave para as espécies, com base da genitália dos machos.

\section{Coelidiana Oman, 1936}

Neocoelidia rubrolineata Baker, 1898. Por designação original.

Kramer (1964), caracterizou Coelidiana da seguinte forma: com carena separando a coroa da face. Coroa, em vista dorsal, variável com comprimento e largura quase iguais ou comprimento excedendo a largura e angulada apicalmente. Ocelo na margem anterior da coroa. Cabeça, incluindo os olhos, mais estreita que o pronoto. Margem posterior do pronoto geralmente denteada. Venação das asas anteriores altamente obscura exceto apicalmente. Coloração de palha a amarelo, no geral. Cabeça, pronoto e escutelo sem máculas, estas quando presentes distintas ou inconspícuas, podendo ser amarelas a vermelho em forma de faixas laterais e/ou longitudinais. Asas anteriores variando de uma cor uniforme até marcadas com marrom escuro ou preto. Genitália masculina: placas subgenitais fusionadas basalmente e freqüentemente por quase toda a sua extensão. Pigóforo, em vista lateral, de forma variável, sem processos dorsais, mas terminando com uma saliência aguda simples ou desenvolvida de comprimento variável; margem ventral com ganchos, espinhos apicais longos ou simples. Tubo anal com ganchos ventrais pareados ou nenhum. Conetivo em forma de "Y". Estilo em vista lateral fortemente enganchado apicalmente. Edeago simples, delgado, ou moderadamente robusto e curvado para cima no ápice.

\section{Chave para machos das espécies de Coelidiana}

A chave apresentada é uma adaptação à de KrAmER (1967: 31) A espécie C. rotundiceps Linnavuori \& Heller, 1961, C. lurida Linnavuori, 1965, C. coronata (Ball, 1916) e C. distinctissima Linnavuori, 1965 não foram incluídas na chave, a primeira por se acreditar que não pertença ao gênero e as outras três por não termos espécimes machos.

1. Edeago com processos ......................................................... 2

1 '. Edeago sem processos ....................................................... 6

2. Edeago com um par de processos basais ou apicais ........... 3

2 '. Edeago com um processo basal .......................................... 4

3. Edeago com um par de processos basais ............ C. patrator

3'. Edeago com um par de processos apicais ........ C. sinopensis
4. Pigóforo com dente na margem ventro-apical; edeago com um pequeno processo ventral, digitiforme ......... C. flavida

4'. Pigóforo não com acima; edeago com processo ventral relativamente grande e com ápice agudo ........................ 5

5. Pigóforo com dente no terço apical da margem ventral; edeago curvado apenas no terço apical ........ C. brasiliensis

5'. Pigóforo com ápice dorsal projetado e terminando pontiagudo; edeago curvado no terço basal e no terço apical ..

C. diminuta sp. nov.

6. Pigóforo terminando, dorsalmente, em uma ponta aguda de comprimento variável e com dente na margem ventral. 7

6'. Pigóforo não como acima ...... 12

7. Edeago com margem ventral irregular ................ C. croceata

7'. Edeago com margem ventral lisa ..................................... 8

8. Pigóforo com apenas um dente margem ventral ............... 9

8'. Pigóforo com dois dentes na margem ventral ........ C.plaga

9. Edeago com curvatura branda, mais acentuada no terço apical; ápice do edeago arredondado ........... . rubrolineata

9'. Edeago não como acima …................................................ 10

10. Edeago com curvatura abrupta no terço basal e ápice retilíneo C. durata

10'. Edeago não curvado, mais ou menos retilíneo ............. 11

11. Edeago não robusto, com curvatura ventral apenas no ápice; tubo anal sem processos C. ferruginea

11'. Edeago robusto com curvatura mais ou menos no terço apical e ápice em vista dorsal com duas projeções laterais; com pequeno processo no tubo anal ............. C. signaticeps

12. Tubo anal com processos .................................................. 13

12 '. Tubo anal sem processos .................................................. 16

13. Processos do tubo anal conspícuos ................................ 14

13'. Processos do tubo anal inconspícuos ............................ 15

14. Pigóforo com projeção delgada, voltada para baixo, com o ápice mais alargado e obtuso ............................. C. ancora

14 '. Pigóforo não como acima .................................... C. colens

15. Tubo anal com processos na base .................... C. bidentata

15'. Tubo anal com processos, porém, não na base.... C. bella sp. nov.

16. Ápice do pigóforo com duas projeções agudas, uma dorsal e outra ventral

16'. Margem posterior do pigóforo não como acima .......... 18

17. Projeções agudas do ápice do pigóforo semelhantes em tamanho C. bimaculata

17 '. Projeção dorsal do ápice do pigóforo mais de duas vezes o tamanho da projeção ventral C. spina

18. Margem posterior do pigóforo truncada ........ C. unipuncta

18'. Margem posterior do pigóforo nunca truncada 19

Revista Brasileira de Zoologia 22 (2): 494-500, junho 2005 

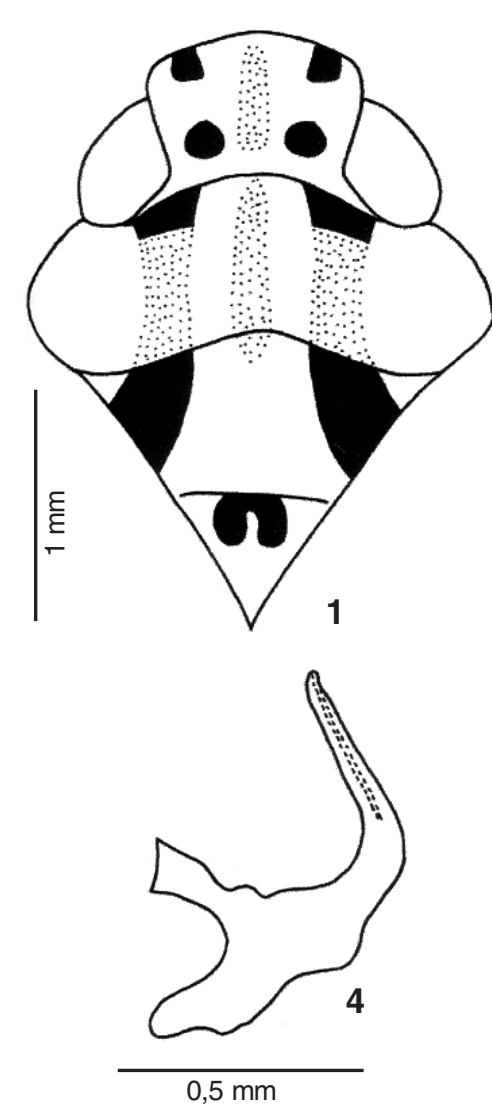
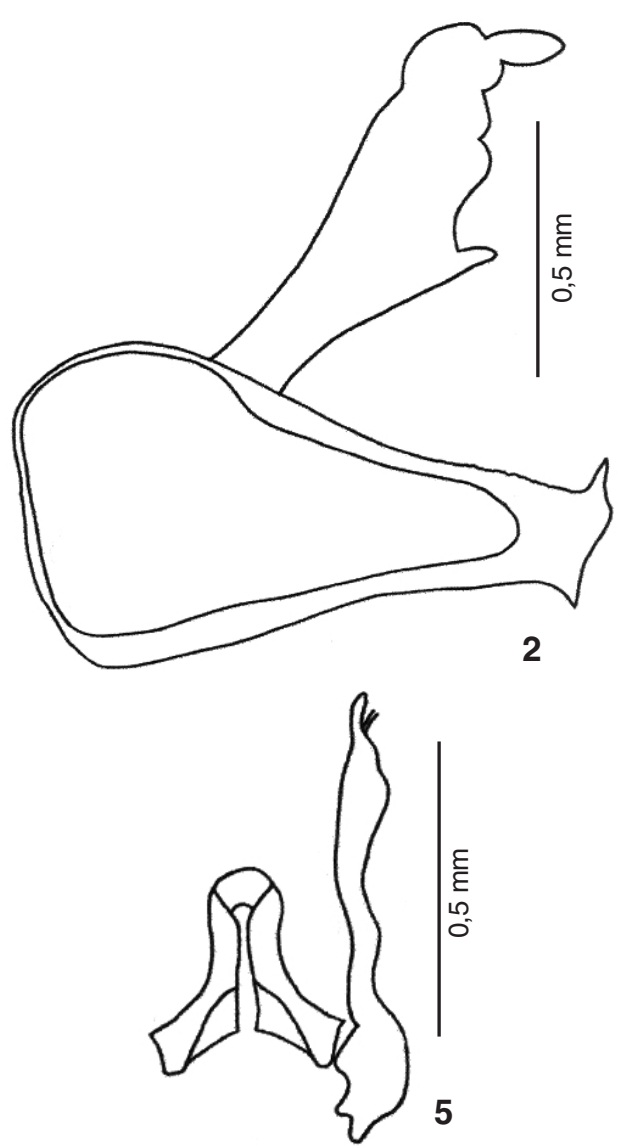

2
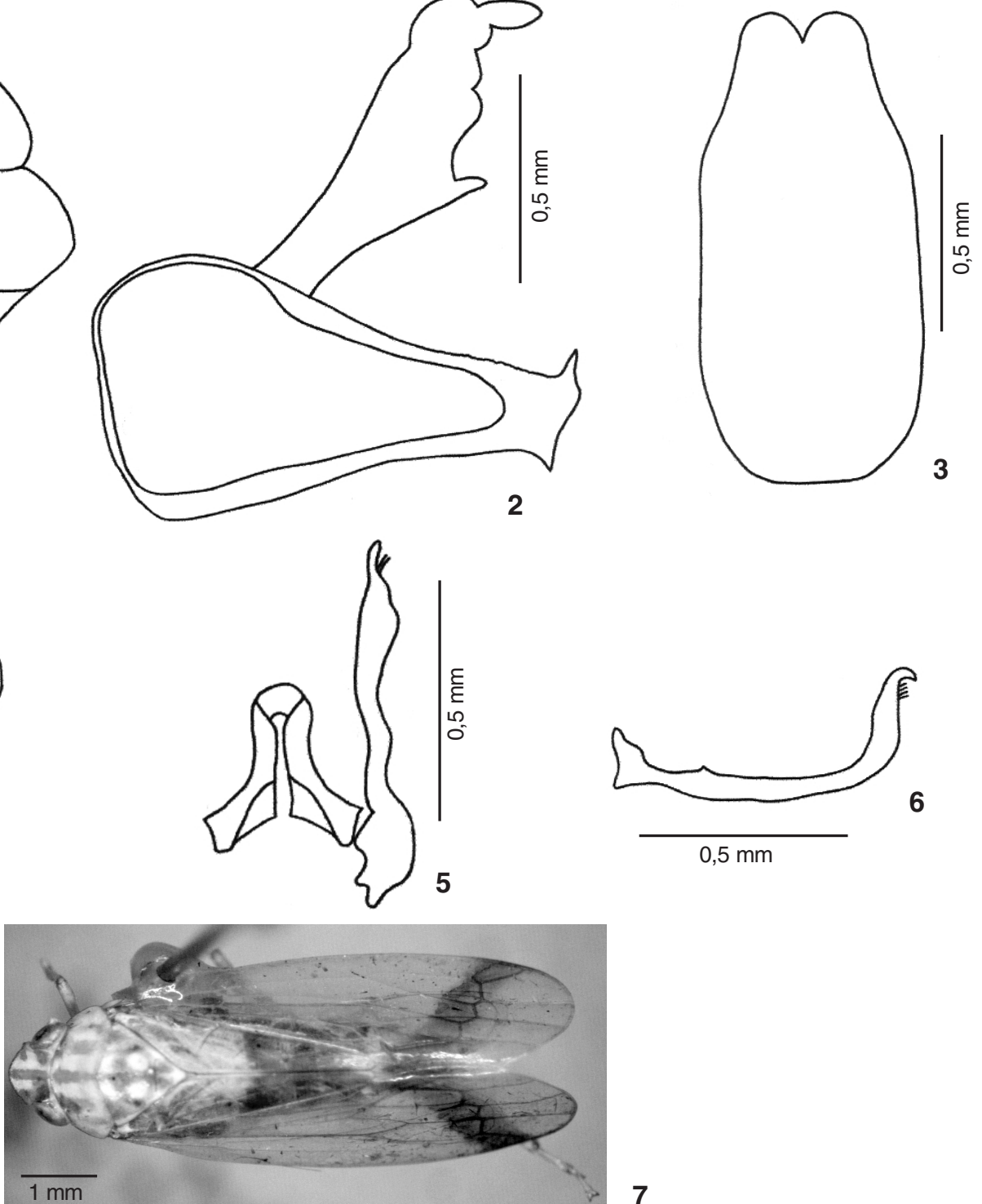

7

Figuras 1-7. Coelidiana bella sp. nov.: (1) cabeça, pronoto e escutelo, vista dorsal; (2) pigóforo, vista lateral; (3) placa subgenital, vista ventral; (4) edeago, vista lateral; (5) estilo e conetivo, vista dorsal; (6) estilo, vista lateral; (7) vista dorsal.

19. Pigóforo longo, margem dorsal no seu terço apical, irregular (crenulada); margem ventral com um dente ventral no terço apical C. stricta sp. nov.

19'. Pigóforo não como acima 20

20. Placa subgenital mais longa do que o pigóforo .. C. undata

20 '. Placa subgenital tão longa quanto ou mais curta do que o pigóforo

21. Pigóforo arredondado apicalmente C. anomala

21'. Pigóforo afilado apicalmente C. krameri

\section{Coelidiana bella sp. nov. Figs $1-7$}

Holótipo macho. BRasiL, Mato Grosso: Sinop, X/1975, M. Alvarenga leg. [DZUP].

Diagnose. Pigóforo com a margem posterior truncada e com dentes, um voltado dorsalmente e outro dirigido para baixo; Edeago sem processos e fortemente curvado dorsalmente.

Holótipo macho. Medidas: comprimento total 8,00; comprimento mediano da cabeça 0,68 ; distância transocular 1,52 ; 


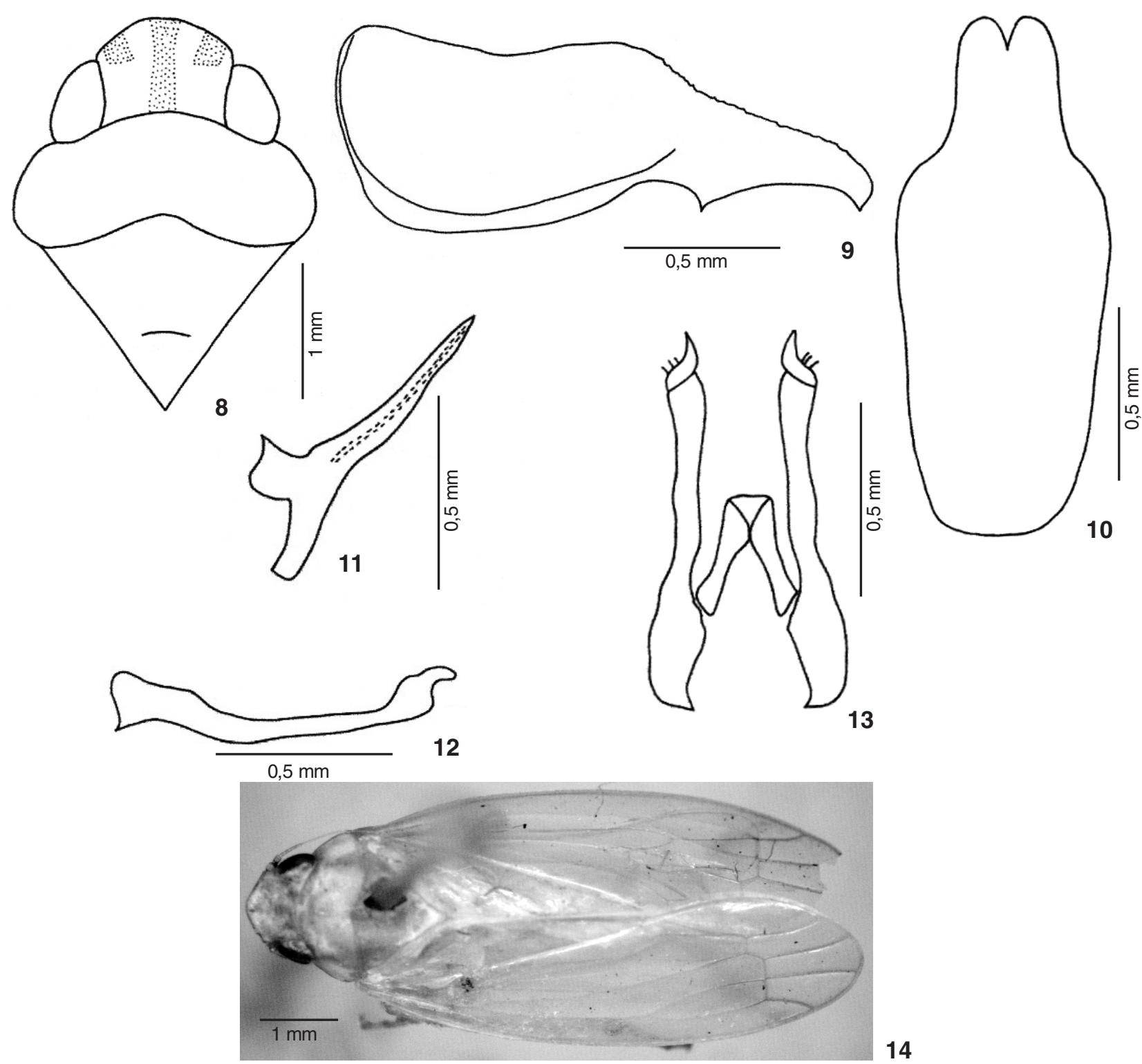

Figuras 8-14. Coelidiana stricta sp. nov.: (8) cabeça, pronoto e escutelo, vista dorsal; (9) pigóforo, vista lateral; (10) placa subgenital, vista ventral; (11) edeago, vista lateral; (12) estilo, vista lateral; (13) estilo e conetivo, vista dorsal; (14) vista dorsal.

distância interocular 0,72 ; comprimento mediano do pronoto 0,72 ; distância entre os úmeros 1,92; largura máxima do escutelo 1,52; comprimento mediano do escutelo 1,36; comprimento das asas anteriores 6,40; largura máxima das asas anteriores 2,00 .

Cabeça, em vista dorsal (Fig. 1), pronunciada, comprimento mediano levemente maior que 4/10 da largura transocular, margem anterior levemente arredondada e com carena na transição entre a coroa e a face; superfície lisa. Ocelos pouco diferenciados, localizados na face, logo abaixo da carena, acima dos lóbulos supra-antenais. Lóbulos supra-antenais não protuberantes dorsalmente, lateralmente carenados e oblíquos. Fronte, em vista lateral, não arqueada; superfície pontuada. Clípeo contínuo com a fronte, de aspecto retangular, em vista lateral, levemente arqueado.

Tórax. Pronoto (Fig. 1) mais largo que a cabeça, com a superfície levemente enrugada; margem anterior arredondada; carena notopleural completa; margem posterior com ligeira reentrância mediana. Escutelo (Fig. 1) com superfície pontuada. Asas anteriores com venação obscura, exceto apicalmente; 
com quatro células apicais.

Genitália. Pigóforo (Fig. 2) aproximadamente retangular, com dois dentes apicais, um dorsal e outro ventral; margem dorsal, apicalmente com pequenas ondulações. Placa subgenital (Fig. 3) inteira com uma reentrância mediana no ápice. Estilos (Fig. 6) curvos apicalmente. Conetivo (Fig. 5) em forma de "Y" invertido e fortemente unido com o edeago. Edeago (Fig. 4) com a base alargada e bífida, formando um ramo dorsal e um ventral; haste afilada para o ápice e fortemente curvada dorsalmente.

Tubo anal com um par de processos, em forma de ganchos, ventrais.

Coloração geral amarela, com marcas de diferentes tons de laranja na coroa, pronoto e escutelo. Asas anteriores (Fig. 7) hialinas, com duas manchas marrons, uma mais ou menos retangular no terço apical do clavo, junto à margem anal e outra, oblíqua no terço apical na altura das células anteapicais.

Comentários. Coelidiana bella sp. nov. é similar a $C$. croceata (Osborn, 1923) diferindo desta por apresentar a haste do edeago fortemente curvada; tubo anal com ganchos e asas anteriores com manchas marrons.

\section{Coelidiana stricta sp. nov. Figs 8-14}

Holótipo macho. BrasiL, Rondônia: Ariquemes, Fazenda Rancho Grande, Cacaulandia, 10/X/1991, Mielke leg. [DZUP]. Parátipo macho. Brasil, Mato Grosso, Sinop, X/1975, M. Alvarenga leg. [DZUP].

Diagnose. Pigóforo, apicalmente unciforme e com a margem ventral, no seu terço apical com um dente voltado para baixo; Edeago simples, sem processos, retilíneo, expandido basalmente formando dois ramos divergentes anteriormente.

Holótipo macho. Medidas: comprimento total 7,80; comprimento mediano da cabeça 0,68; distância transocular 1,56; distância interocular 0,92; comprimento mediano do pronoto 0,76; distância entre os úmeros 2,16; largura máxima do escutelo 1,60; comprimento mediano do escutelo 1,40; comprimento das asas anteriores 6,20; largura máxima das asas anteriores 2,16 .

Morfologia externa como em C. bella sp. nov.

Genitália. Pigóforo (Fig. 9) mais ou menos triangular, alongado, com dois dentes, um no terço apical da margem ventral e outro unciforme, apical e voltado para baixo; margem dorsal, no terço apical, crenulada; com uma esclerotinização mais acentuada basalmente e no terço anterior da margem ventral. Placa subgenital (Fig. 10) inteira, com uma pequena reentrância mediana no ápice e um forte estreitamento no seu terço apical. Estilos (Fig. 12 e 13) delgados, longos, curvados apicalmente. Conetivo (Fig. 13) em forma de "V" invertido. Edeago (Fig. 11) curto, sem processos, expandido basalmente formando dois ramos divergentes, do terço basal até o ápice retilíneo, obtuso apicalmente.

Tubo anal sem processos.

Revista Brasileira de Zoologia 22 (2): 494-500, junho 2005
Coloração geral amarelo-pálida, com três manchas alaranjadas na coroa, sendo a mediana a mais longa, as outras duas, no terço anterior e localizadas paralelas à mediana. Asas anteriores amarelo-hialinas, com veias amareladas.

Comentários. Coelidiana stricta sp. nov. é semelhante a Coelidiana plaga DeLong \& Kolbe, 1975 diferindo, principalmente, pela presença de manchas alaranjadas na coroa e a ausência de processos no pigóforo.

\section{Coelidiana diminuta sp. nov. Figs 15-21}

Holótipo macho. Brasil, São Paulo: Bebedouro, 15/V/1998, Giustoli, T. A. col., Café-Malaise [DZUP]. Parátipos 18 machos, mesmos dados do holótipo [DZUP].

Diagnose. Pigóforo truncado apicalmente, com uma forte projeção pontiaguada apico-dorsal. Edeago curvo, com processo ventro-basal, longo e sinuoso.

Holótipo macho. Medidas: comprimento total 5,50; comprimento mediano da cabeça 0,52 ; distância transocular 1,14 ; distância interocular 0,66; comprimento mediano do pronoto 0,42; distância entre os úmeros 1,28; largura máxima do escutelo 0,94; comprimento mediano do escutelo 0,70; comprimento das asas anteriores 4,30; largura máxima das asas anteriores 1,12 .

Cabeça, em vista dorsal, (Fig. 15) pronunciada, comprimento mediano levemente maior que 4/10 da largura transocular, margem anterior arredondada e com carena na transição da coroa com a face; superfície pontuada. Ocelos não evidentes. Lóbulos supra-antenais não protuberantes dorsalmente e lateralmente carenados e oblíquos. Fronte, em vista lateral, não arqueada; superfície pontuada; clípeo contínuo com a fronte, de forma retangular e, em vista lateral, não arqueado. Asas anteriores com venação obscura. Demais características como em Coelidiana bella sp. nov.

Genitália do macho. Pigóforo (Fig. 16) truncado apicalmente, com uma forte projeção pontiaguda dorsalmente, ventralmente, com um pequeno dente; na base da projeção dorsal há um pequeno dente. Placa subgenital (Fig. 17) inteira com uma pequena reentrância mediana no seu ápice. Estilos (Fig. 20) mais longos do que o conetivo, ápice pontiagudo e, em vista lateral, curvado apicalmente. Conetivo (Fig. 20) em forma de " $Y$ " invertido, com ramo apical muito mais curto do que os ramos laterais. Edeago (Fig. 18) curvo, voltado para trás, apicalmente com leve expansões laterais (Fig. 19), com processo ventro-basal longo e sinuoso.

Tubo anal sem processos.

Coloração geral amarelo-palha. Asas anteriores hialinas.

Comentários. Coelidiana diminuta sp. nov. é semelhante à Coelidiana brasiliensis Linnavuori, 1965, diferindo no formato do pigóforo, que apresenta um dente abaixo da forte projeção da margem dorso-posterior, e do edeago, este último sendo curvado e voltado para trás, processo ventro-basal, longo e sinuoso. 

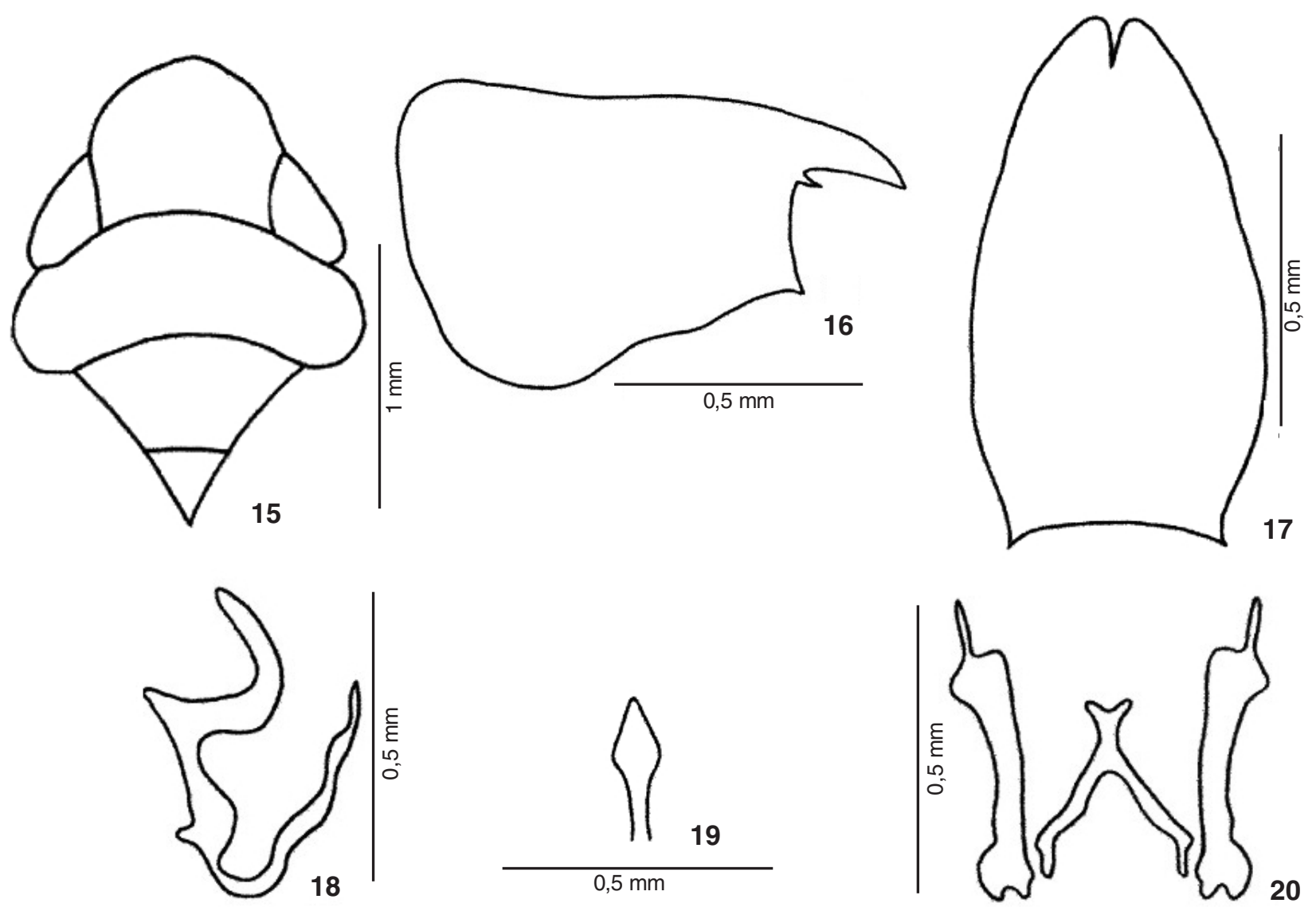

20

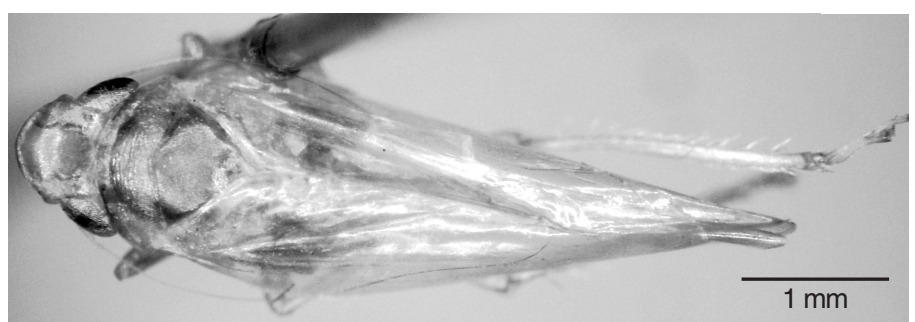

Figuras 15-21. Coelidiana diminuta sp. nov.: (15) cabeça, pronoto e escutelo, vista dorsal; (16) pigóforo, vista lateral; (17) placa subgenital, vista ventral; (18) edeago, vista lateral; (19) ápice do processo do edeago, vista posterior; (20) estilo e conetivo, vista dorsal; (21) vista dorsal.

A seguir lista-se a inclusão de uma espécie e novas ocorrências para as espécies do gênero.

Coelidiana sinopensis (Chiamolera \& Cavichioli, 2000a) comb. nov.

Esta espécie foi descrita no gênero Biza, Walker, é aqui transferida para Coelidiana principalmente pela forma da genitália do macho. - Brasil: Amazonas, Rio Solimões, Lago do José (proximidades de Manaus); 9-VIII-1979, J. Adis et al. leg. (INPA) - um macho; Amazonas, Rio Janauaca (40 Km SW Manaus), 10-03-1979 (INPA) - um macho.

Coelidiana croceata (Osborn, 1923) - São Paulo, Bebedouro, 22/
II/1999, malaise (café) (DZUP) - doze machos.

Coelidiana brasiliensis Linnavuori, 1965 - Estado do Rio de Janeiro, Itatiaia, 5/II/1957 (DZUP) - dois machos; Brasil: Paraná, Foz do Iguaçu, 3/XII/1966 (DZUP) - um macho.

Coelidiana ferruginea Chiamolera \& Cavichioli, 2000b - Roraima, Rio Uraricoera, Ilha de Maracá, 02-13/V/1987 (INPA) - um macho; Amazonas. Coari, Rio Urucu, Petrobrás, RUC-30, 07-14/IX/1992, P.F. Buhrnheim \& N.O. Aguiar leg. (INPA) - um macho; Amazonas, Coari, Rio Urucu, LUC-09, 451'56"S/6504'56"W, 25/I-10/ II/1995, P. Bührnheim et al. leg. (INPA) - um macho. 


\section{REFERÊNCIAS BIBLIOGRÁFICAS}

Chiamolera, L.D.B. \& R.R. Cavichioli. 2000a. Biza sinopensis sp. n. (Hemiptera, Auchenorrhyncha, Neocoelidiinae) do Mato Grosso, Brasil. Revista Brasileira de Zoologia, Curitiba, 17 (1): 61-63.

Chiamolera, L.D.B. \& R.R. CAVichioli. 2000b. Coelidiana ferruginea sp. n. (Hemiptera, Auchenorrhyncha, Neocoelidiinae) do Estado de Mato Grosso, Brasil. Revista Brasileira de Zoologia, Curitiba, 17 (2): 539-542.

Delong, D.M. 1953. A synopsis of the tribe Neocoelidinii in the Americas (Homoptera-Cicadellidae). Lloydia, Cincinnati, 16 (2): 93-131.

Delong, D.M. \& A.B. KolbE. 1975. Three new species of Neocoelidiinae (Homoptera-Cicadellidae) from Panama and Peru. Journal of the Kansas Entomological Society, Manhattan, 48 (1): 124-126.

FreytaG, P.H. 2000. A new species of Coelidiana (Homoptera: Cicadellidae) from the Galapagos Islands. Entomological News, Philadelphia, 111 (5): 325-327.

Hamilton, K.G.A. 1981. Morphology and evolution of the rhynchotan head (Insecta: Hemiptera, Homoptera). Canadian Entomologist, Ottawa, 113 (11): 953-974.

Kramer, J.P. 1959. An elucidation of the neotropical genus Chinaia with a key to males and a new allied genus. (Homoptera: Cicadellidae: Neocoelidiinae). Proceedings of the Biological Society of Washington, D.C., 72: 23-32.

KRAMER, J.P. 1964. A generic revision of the leafhopper subfamily Neocoelidiinae. (Homoptera: Cicadellidae). Proceedings of the United States National Museum, Washington, D.C., 115 (3484): 259-287.

KRAMER, J.P 1967. New neotropical Neocoelidiinae with keys to the species of Coelidiana, Xenocoelidiana, and Nelidina (Homoptera:Cicadellidae). Proceedings of the Entomological Society of Washington, D.C., 69 (1): 31-46

Linnavuori, R. \& F. Heller. 1961. Beitrag zur Cicadelliden-Fauna von Peru. Stuttgarter Beiträge Zur Naturkunde, Stuttgart, 67: 1-14.

LiNNAVUORI, R. 1965. On some new or interesting Neotropical Homoptera of the family Cicadellidae. Bonner Zoologische Beiträge, Bonn, 11 (1-2): 137-150.

Mejdalani, G. 1998. Morfologia externa dos Cicadellinae (Homoptera: Cicadellidae): Comparação entre Versigonalia ruficauda (Walker) (Cicadellini) e Tretogonia cribrata (Melichar) (Proconiini), com notas sobre outras espécies e análise da terminologia. Revista Brasileira de Zoologia, Curitiba, 15 (2): 451-544.

Oman, P.W. 1936. A generic revision of American Bythoscopinae and South American Jassinae. Kansas University Science Bulletin, Lawrence, 24 (16): 343-420.

Oman, P.W. 1949. The Neartic leafhoppers (Homoptera: Cicadellidae). A generic classification and check list. Memoirs of the Entomological Society of Washington, D.C., 3: 1253.

YounG, D.A. 1968. Taxonomic study of the Cicadellinae (Homoptera: Cicadellidae), Part 1, Proconiini. Bulletin of the United States National Museum, Washington, D.C., 261: $1-287$.

Recebido em 12.IV.2004; aceito em 23.V.2005. 